\title{
Regulators of Starch Biosynthesis in Cereal Crops
}

\author{
Ruiqing Li ${ }^{1,2}$, Yuanyuan Tan ${ }^{3}$ and Huali Zhang ${ }^{1, *}$ \\ 1 State Key Laboratory of Rice Biology, Chinese National Center for Rice Improvement, China National Rice \\ Research Institute, Hangzhou 310029, China; liruiqing@ahau.edu.cn \\ 2 College of Agronomy, Anhui Agricultural University, Hefei 230036, China \\ 3 National Key Laboratory of Rice Biology, Institute of Crop Sciences, College of Agriculture and Biotechnology, \\ Zhejiang University, Hangzhou 310029, China; tanyy@zju.edu.cn \\ * Correspondence: zhanghuali621@126.com
}

\section{check for}

updates

Citation: Li, R.; Tan, Y.; Zhang, H. Regulators of Starch Biosynthesis in Cereal Crops. Molecules 2021, 26, 7092. https://doi.org/10.3390/

molecules26237092

Academic Editor: Lesław Juszczak

Received: 29 August 2021

Accepted: 21 November 2021

Published: 24 November 2021

Publisher's Note: MDPI stays neutral with regard to jurisdictional claims in published maps and institutional affiliations.

Copyright: (c) 2021 by the authors. Licensee MDPI, Basel, Switzerland. This article is an open access article distributed under the terms and conditions of the Creative Commons Attribution (CC BY) license (https:/ / creativecommons.org/licenses/by/ $4.0 /)$.

\begin{abstract}
Starch is the main food source for human beings and livestock all over the world, and it is also the raw material for production of industrial alcohol and biofuel. A considerable part of the world's annual starch production comes from crops and their seeds. With the increasing demand for starch from food and non-food industries and the growing loss of arable land due to urbanization, understanding starch biosynthesis and its regulators is essential to produce the desirable traits as well as more and better polymers via biotechnological approaches in cereal crops. Because of the complexity and flexibility of carbon allocation in the formation of endosperm starch, cereal crops require a broad range of enzymes and one matching network of regulators to control the providential functioning of these starch biosynthetic enzymes. Here, we comprehensively summarize the current knowledge about regulatory factors of starch biosynthesis in cereal crops, with an emphasis on the transcription factors that directly regulate starch biosynthesis. This review will provide new insights for the manipulation of bioengineering and starch biosynthesis to improve starch yields or qualities in our diets and in industry.
\end{abstract}

Keywords: starch biosynthesis; cereal crops; transcription factors; regulator; endosperm

\section{Introduction}

As a fundamental commodity, starch was and is still widely used for human consumption in food and non-food industries [1,2]. Since starch is the major storage carbohydrate and generally accumulated in the heterotrophic starch-storing organs of crops [3-5], a large amount of starch is sourced from the attainable parts of staple crop plants [5], especially for cereal seeds, roots, and tubers. Among them, cereal seeds make up most of the worldwide annual starch production.

Starch is composed of amylose and amylopectin glucan polymers, which are packaged to form the insoluble semi-crystalline starch granules [6]. Starch synthesized in cereal crops contains at least two types, termed transitory starch and storage starch. Transitory starch is usually found in the plastid of photosynthetic organs and displays circadian turnover regulation with diurnal cycles [7]. While the storage starch is synthesized in the amyloplasts of non-photosynthetic sink tissues (i.e., seed endosperm), and requires the supply of sucrose and ATP from the source organs (i.e., leaves) [5]. Interestingly, some common regulatory factors of starch synthesis exist between chloroplasts and amyloplasts. For example, the expression of starch biosynthetic genes, i.e., GBSSI, was partly mediated by tetrapyrrole intermediates, i.e., heme, in endosperm during early seed development in rice [8], suggesting potential shared regulatory networks in various plastids.

The process of starch biosynthesis in crops requires tight cooperation of various starch biosynthetic enzymes, and coordinates with other metabolisms. Until now, a great number of genes involved in starch biosynthesis have been identified in various cereals. However, despite these findings, the regulatory factors underlying starch synthesis are still poorly 
understood, especially regarding the regulation of starch biosynthetic genes. Therefore, the screening and identification of key regulators is vital to understanding the fundamental regulatory mechanism underlying starch synthesis. Here, we comprehensively provide an update on current knowledge on the pivotal spatiotemporal-dependent regulators of starch biosynthesis in cereal crops with a focus on transcription factors directly regulating starch biosynthesis, which will provide new insights into cereal starch yield or quality improvement on our diet as well as in industry.

\section{Transcription Factors Directly Regulating Starch Biosynthesis}

Starch biosynthesis is a complex process and requires various functional enzymes, which are regulated by transcription factors (TFs) and/or other regulators (Figure 1). Transcription factors mediate gene expression through direct combination with various domains in the promoter regions of target genes based on different environmental factors [9]. Likewise, regulation of the starch synthetic genes is also subjected to the regulation of many TF families (Figure 1), including basic leucine zipper transcription (bZIP) [10,11], APETALA2/Ethylene-Responsive Factor (AP2/ERF) [12-14], NAC (no apical meristem (NAM), ATAF1/2, cup-shaped cotyledon (CUC2)) [15], MYB [16], GRAS [17], and DNA binding with one finger (DOF) $[18,19]$.

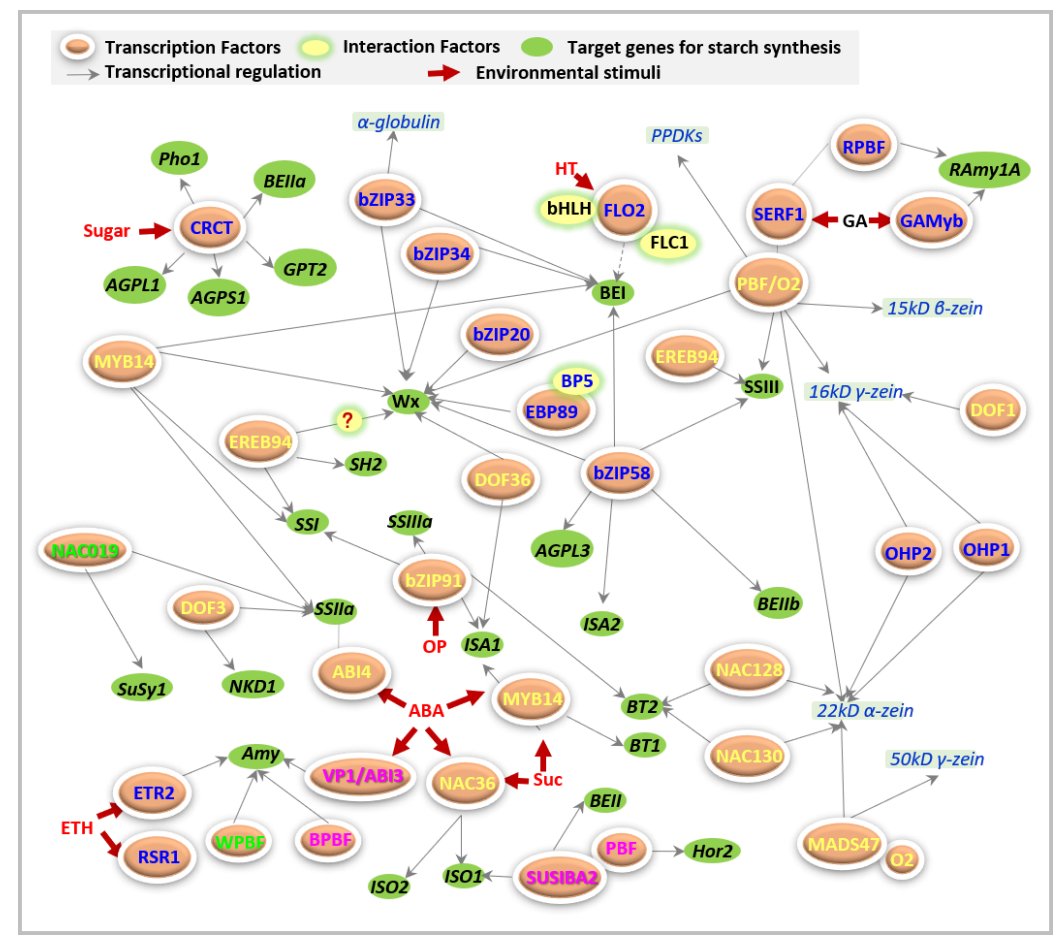

Figure 1. Overview of the regulators of starch metabolism in cereal crops. The figure was created based on the published literature (until 28 August 2021). The reported regulators and their target genes from different cereals were collected to build potential regulatory networks of starch metabolic genes. Starch biosynthesis involves a great deal of enzymatic and non-enzymatic proteins, which constitutes a very complex network. This process requires many regulators to match the providential functioning of these starch biosynthetic enzymes. Nowadays, dozens of transcription factors have been reported to directly regulate starch synthesis, i.e., bZIP58, NAC019, MYB14, FLO2, SUSIBA2, and so on. Besides, some regulators also control starch synthesis through the formation of proteins and sucrose, including MADS47, DOF1, and so on. Various regulators prefer to be activated in response to different fluctuating environments, such as hormone levels (i.e., ethylene, ETH; abscisic acid, ABA; gibberellin, GA), osmotic pressure (OP), sugar (i.e., sucrose, SUC), and high temperature (HT), etc. Regulators that exist in rice, maize, wheat, and barley are shown in blue, yellow, purple, and green color letters, respectively. 
Transcriptional regulation of starch biosynthesis varies with the environment, such as phytohormones and sucrose, and shows spatial-temporal gene targeting in different cereal crops. Based on the expression patterns in various tissues, genes involved in starch synthesis can be divided into two types $[14,20]$. The type I genes are more likely to be expressed in sink organs (e.g., endosperm), while the type II genes are abundantly expressed in source organs, including the root, seedling, leaf, ovary, and embryo [14,20]. Accordingly, the TF members of the bZIP, AP2/ERF, MYB, or NAC families always co-express with type I, whereas the bHLH (for basic helix-loop-helix), homeobox, or SET (Su(var)3-9, Enhancer-of-zeste, and Trithorax) families mostly co-express with type II [14]. These findings indicate that TF-involved starch biosynthesis has somewhat tissue-specific characteristics.

\section{1. bZIP}

bZIP factors are the first identified transcription factors to regulate starch biosynthesis [21,22], and they appear to be one of the main regulators of this process. bZIP regulators have been well characterized in several crops, including Oryza sativa L. [23,24], Zea mays L. [10], Hordeum vulgare L. [25], and Triticum aestivum L. [26,27]. bZIP factors play multiple roles during starch synthesis, but their precise roles vary in different species. This divergence includes a set of target genes and the binding affinity. For example, one bZIP transcription factor, OsbZIP58, regulates six genes during starch metabolism in rice $[10,28,29]$, while the identified candidate TabZIPs are only involved in the regulation of granule-bound starch synthase I (GBSSI)/Waxy (Wx) and branching enzyme II (BEII) during starch biosynthesis in wheat [26]. Furthermore, the binding motif of bZIPs seems to be considerably the same in rice [11], barley [25], and maize [23], but it is still not clear whether a similar phenomenon exists in other cereal species.

bZIPs show broad affinities with different motifs in the process of regulating starch biosynthesis. A well-studied bZIP in rice, OsbZIP58 (also called RISBZ1 or OsSMF1) [28,29], has been revealed as a regulator of starch biosynthetic genes [11]. OsbZIP58 interacts with different motifs to regulate starch biosynthesis (Figure 2 and Table 1), and mainly functions through three manners, including (i) by binding to the ACGT (CCACGTG/C) element to regulate the synthesis of storage proteins and free lysine [18,30,31]; (ii) by direct combination with the motif of ACGT to regulate the expression of ADP-glucose pyrophosphorylase large subunit 3 (OsAGPL3), OsGBSSI/Wx, starch synthase IIa (OsSSIIa), BEI, OsBEIIb, and Isoamylase-type starch debranching enzyme 2 (ISA2) [11]; and (iii) by activating the synthesis of several seed storage proteins and the expression of two NAC transcription factors associated with starch biosynthesis $[29,30]$ by binding with the GCN4 or ACGT motif. Moreover, several other bZIPs also exhibit broad affinity to the GCN4 or ACGT motif [29] upon their divergent functions. OsbZIP20 (RITA, rice transcription activator-1) interacts with the palindromic ACGT elements to mediate starch synthesis [24], whereas OsbZIP33 (rice endosperm basic leucine zipper, REB) shows binding specificity with ACGT elements in the promoters of BEI and GBSSI during starch synthesis [32]. Similar phenomena also exist in maize. Maize Opaque2 (O2) [10] could directly regulate starch synthase III (SSIII) and indirectly regulate SSIIa and BEI via interaction with prolamin-boxbinding factor $(\mathrm{PBF})$ to mediate starch biosynthesis at transcriptional levels. Moreover, ZmbZIP91 [33] binds to the ACTCAT elements to regulate starch synthesis genes ( $p$ AGPS1, pSSI, pSSIIIa, and pISA1). 


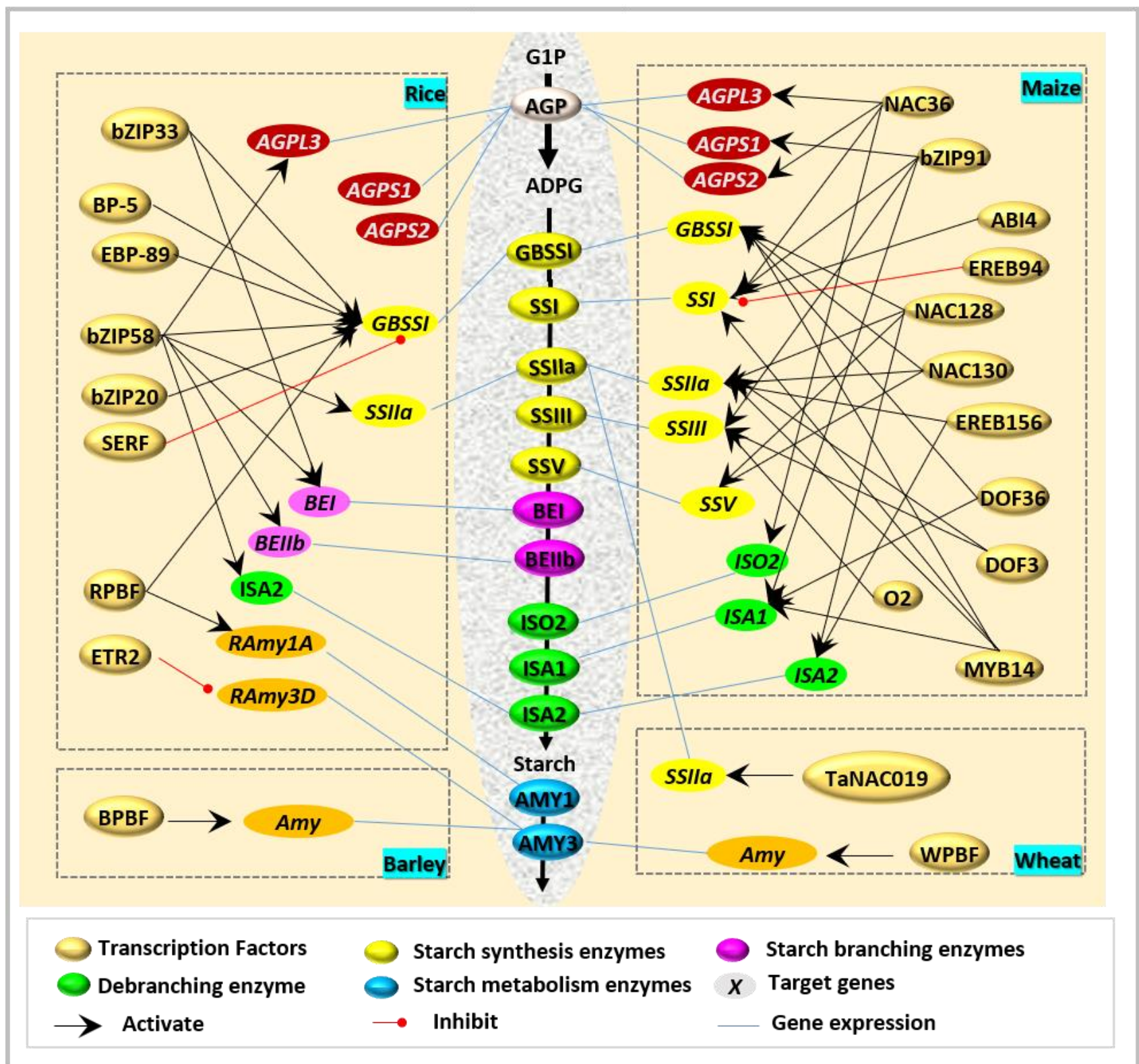

Figure 2. TF-regulating genes that encode starch biosynthetic enzymes. The formation of starch in cereal crops is the result of a series of enzymatic reactions, which require the cooperation of many TFs. Regulation of TFs on starch biosynthetic genes showed the following patterns: (i) the same gene was regulated by several TFs, i.e., GBSSI or Wx to RPBF, bZIP58, $B P-5$, and EBP-89, etc.; (ii) several genes were regulated by the same TF, i.e., ZmNAC128 and ZmNAC130; (iii) the regulation of TFs was also affected by various environments. Besides, there were regulatory differences of TFs in different cereals. For example, OsbZIP58 was close to ZmbZIP91 and O2, but their target genes were divergent. 
Table 1. Transcriptional factors directly regulating starch biosynthesis in cereal crops.

\begin{tabular}{|c|c|c|c|c|c|c|}
\hline TF & Types & $\begin{array}{l}\text { Binding } \\
\text { Domains }\end{array}$ & Target Genes & Species & $\begin{array}{c}\text { Specific } \\
\text { Expressed } \\
\text { Tissues }\end{array}$ & References \\
\hline REB/bZIP33 & bZIP & ACGT & $\begin{array}{c}\text { GBSSI }(W x) \text { and } \\
B E I\end{array}$ & Rice & & [32] \\
\hline RISBZ1/bZIP58 & bZIP & ACGT & $\begin{array}{l}\text { AGPL3, GBSSI } \\
(W x), \text { SSIIa, BEI, } \\
B E I I b \text {, and ISA2 }\end{array}$ & Rice & Endosperm & {$[11,28,29]$} \\
\hline OsbZIP20 & bZIP & ACGT & GBSSI $(W x)$ & Rice & Endosperm & [24] \\
\hline ZmbZIP91 & bZIP & ACTCAT & $\begin{array}{c}\text { AGPS1, SSI, } \\
\text { SSIIIa, and ISA1 }\end{array}$ & Maize & & [33] \\
\hline TabZIP & bZIP & & $\begin{array}{c}\text { GBSSI }(W x) \text { and } \\
\text { BEII }\end{array}$ & Wheat & Endosperm & [26] \\
\hline TabZIP28 & bZIP & CACGTC & AGPase & Wheat & Endosperm & [27] \\
\hline $\mathrm{O} 2$ & bZIP & & SSIII & Maize & & [10] \\
\hline OsETR2 & $\mathrm{AP} 2 / \mathrm{ERF}$ & & RAmy3D & Rice & Endosperm & {$[34]$} \\
\hline OsSERF & $\mathrm{AP} 2 / \mathrm{ERF}$ & & $R P B F, G B S S I$ & Rice & Endosperm & [35] \\
\hline OsBP-5 & MYC-like & CAACGTG & GBSSI $(W x)$ & Rice & Endosperm & [12] \\
\hline OsEBP-89 & $\mathrm{AP} 2 / \mathrm{ERF}$ & GCCAAC & GBSSI $(W x)$ & Rice & Endosperm & [12] \\
\hline HvVP1/ABI3 & $\mathrm{AP} 2 / \mathrm{ERF}$ & & Amy6.4 & Barley & & [36] \\
\hline ZmABI4 & $\mathrm{AP} 2 / \mathrm{ERF}$ & ACCCG & SSI & Maize & Endosperm & [37] \\
\hline ZmEREB156 & $\mathrm{AP} 2 / \mathrm{ERF}$ & & SSIIIa & Maize & Endosperm & [38] \\
\hline ZmEREB94 & $\mathrm{AP} 2 / \mathrm{ERF}$ & & SSI & Maize & & [39] \\
\hline ZmNAC36 & NAC & & $\begin{array}{c}\text { AGPL2, AGPS2, } \\
\text { SSI, GBSSIIb, } \\
\text { and ISO2 }\end{array}$ & Maize & Endosperm & [15] \\
\hline ZmNAC128 & NAC & ACGCAA & $\begin{array}{c}\text { BT2, Zpu1, } \\
\text { GBSSI, Sh2, } \\
\text { SSV, ISA2, and } \\
\text { SSIIa }\end{array}$ & Maize & Endosperm & {$[40]$} \\
\hline ZmNAC130 & NAC & ACGCAA & $\begin{array}{c}\text { BT2, Zpu1, } \\
\text { GBSSI, Sh2, } \\
\text { SSV,ISA2, and } \\
\text { SSIIa }\end{array}$ & Maize & Endosperm & {$[40]$} \\
\hline TaNAC019 & NAC & & SSIIa, SuSy1 & Wheat & Endosperm & [41] \\
\hline ZmMYB14 & MYB & & BT1 & Maize & Endosperm & [16] \\
\hline SUSIBA2 & WRKY & SURE & BEII, ISO1 & Barley & Endosperm & [42] \\
\hline $\mathrm{RPBF}$ & DOF & & GBSSI & Rice & Endosperm & [5] \\
\hline $\mathrm{RPBF}$ & DOF & TGTAAAG & $R A m y 1 A$ & Rice & Endosperm & [35] \\
\hline ZmDOF3 & DOF & AAAG & SSII $a$ and SSIII & Maize & Endosperm & [16] \\
\hline ZmDOF36 & DOF & $\begin{array}{l}\text { DOF core } \\
\text { elements }\end{array}$ & GBSSI, ISA1 & Maize & Endosperm & [43] \\
\hline $\mathrm{BPBF}$ & DOF & TGTAAAG & $\alpha$-amylase & Barley & & {$[19,44]$} \\
\hline WPBF & DOF & TGTAAAG & $\alpha$-amylase & Wheat & & {$[45]$} \\
\hline
\end{tabular}

Besides, the functions of bZIPs depend on tissue types to some extent. OsZIP58 shows highly endosperm-dependent expression during seed development $[11,28]$, but its highly orthologous genes (e.g., ZmbZIP60, ZmbZIP16, ZmbZIP17, ZmbZIP91) [33] are widely expressed in all types of tissues in maize. Simultaneously, TabZIP [26] and one TubZIP28 and its homolog from Triticum aestivum, TabZIP28 [27], were also reported to positively regulate starch biosynthesis (Table 1 ).

Interestingly, ZmbZIP91 [33] and O2 [10] are the two closest homologous bZIP transcription factors of OsbZIP58. However, their function seems not to be fully in line with OsZIP58, and has divergent target genes and tissue dependence. ZmbZIP91 could bind to the ACTCAT directly to regulate the expression of AGPS1, SSI, SSIIIa, and ISA1 during starch synthesis [33], while O2 [10] usually combines with other factors in the regulation of starch biosynthesis (Figure 2). 
In addition to the heterodimers of bZIPs (e.g., O2) and DOF family factors (e.g., PBF), the MYC proteins also often interact with the ethylene-responsive element-binding protein (EREBP) family in their regulatory functions during starch biosynthesis. For example, one MYC-like protein, OsBP-5, has been reported to interact with the OsEBP-89 (Oryza sativa EREBP clone 89) protein to regulate the $W x$ gene expression in rice [12]. The binding motifs of rice-binding protein 5 (OsBP-5; CAACGTG) is in close proximity to OsEBP-89 (GCCAAC) in the $W x$ promoter [12]. However, the precise affinity and specificity of different binding motifs remain to be further studied.

\section{2. $A P 2 / E R F$}

$\mathrm{AP2} / \mathrm{ERFs}$ serve as one key regulator in the ethylene- and its receptor-mediated signals [16], and is also involved in starch metabolism and accumulation [34,46]. Nowadays, the AP2/ERF family includes three individual subfamilies (ERF, AP2, and RAV) [39]. Among them, ERF factors have been well demonstrated to regulate starch biosynthesis in cereal crops, e.g., Oryza sativa L. [14,34], Zea mays L. [37,39], Hordeum vulgare L. [36], and Triticum aestivum L. [13]. In general, the AP2/ERF factors can combine with DRE, GCC, or CAACA box [47] in the promoter regions of target starch synthetic genes.

AP2/ERF factors probably function through the coordination between different biological processes. One AP2/EREBP-type regulator, Rice Starch Regulator1 (RSR1), has been reported to negatively regulate starch synthesis-associated genes both in wheat [13] and rice [14], but its regulatory mechanism is still unknown. Moreover, OsRSR1 is not only co-expressed with starch synthesis but also co-expressed with most of the genes involved in photosynthesis in leaves. One possible explanation is that starch is the primary product of photosynthesis, which is regulated through chloroplast formation and chlorophyll biosynthesis [14]. Other evidence is from ZmABI4 (ABA Insensitive 4) in maize. As an AP2/ERF family member, ZmABI4 had negative effects on the transcriptional abundance of photosynthesis-associated nuclear genes [48]. Therefore, the tight association between photosynthesis and starch biosynthesis is required for the precise regulatory mechanisms in response to various tissues and environments.

Multiple AP2/ERF factors usually regulate the starch synthesis genes through the induction of phytohormones, including ethylene, abscisic acid (ABA), and gibberellin (GA; Figure 1 and Table 1). Two subfamily II ethylene receptors, ETR2 and Sub1C, are reported to promote starch accumulation by depressing the $\alpha$-amylase gene $R A m y 3 D$ in rice internodes [34] and leaves [38]. These processes are in response to ethylene-dependent developmental stages, employing a common signaling pathway of OsETR2-OsGI [34].

ABA-induced AP2/ERF in starch synthesis includes at least two TFs, EREB and ABI (ABA insensitive; Figure 2). Starch synthesis is positively associated with the ABA level in rice [49], wheat [50], and barley [51]. ABA plus sucrose-induced ZmEREB156 could directly bind to the promoter of ZmSSIIIa to positively mediate starch synthesis [52]. On the contrary, ZmEREB94 has negative effects on starch synthesis through direct combination with the ZmSSI promoter and indirect regulation of ZmSh2 and ZmGBSSI during seed development [39]. The ABA-mediated signaling also depends on three ABI transcription factors (ABI3-ABI5) during seed development [36,37,53,54]. ABI3 [36] and ABI4 [37] regulate starch synthesis via mediation of the expression of GAMYB and SSI genes, respectively. However, ABI3, also named viviparous-1 (VP1), was previously characterized as one regulator of seed development in maize $[55,56]$ and then found to command different spatiotemporal expression pattern specificities in barley [36]. HvABI3/VP1 mediates the GAMYB/BPBF-activated Hor2 (For B-hordeins) expression in developing endosperm and activates the GAMYB-mediated Amy6.4 expression in post-germinative reserve mobilization [36]. The ABA-induced ABI4 also interacts with a CACCG box in the promoter of ZmSSI [37] to mediate starch synthesis. Besides, many other binding locations, including the coupling element1 (CE1)-like motif (CACCK) [57], the S box (CACYKSCA) [48], and the CCAC motif [58,59], are also involved in the regulation of gene expression induced by sugar or ABA. Thus, ABI4 might function with different motifs through various signaling 
pathways, depending on the divergence from tissues, organs, and species, as well as the developmental stages.

Several AP2/ERF TFs are also induced by GA in starch synthesis, i.e., MYB and SALTRESPONSIVE ERF1 (SERF1; Figure 2). GAMYB is a gibberellin-induced transcription factor that activates seed storage genes and hydrolase genes by recognizing the GARE motif [44,60,61]. Another gibberellin-mediated AP2 family TF, rice SERF1, also participated in the regulation of starch biosynthesis [35], and negatively mediated the accumulation and remobilization of starch through the direct regulation of RPBF and GBSSI in the presence of GA [35]. RPBF is one of the P-box binding DOFs [25], and thereby, we will elaborate on its functions in the section of "DOF (DNA binding with one finger) proteins".

Obviously, phytohormone-induced transcriptional regulation requires cooperation with a different set of TFs in accord with their balance. This is also found in other cereal species. For example, OsEBP89 can form a heterodimer with one MYC transcriptional factor, OsBP-5, to regulate GBSSI expression synergistically in rice, and the GCCAAC binding box of OsEBP89 is next to the CAACGTG binding motif of OsBP-5 in the promoter of GBSSI [12]. Besides, as a key enzyme for starch synthesis, GBSSI has several different motifs (e.g., P-box and GCN4) in its regulatory regions, so multiple TFs, including RISBZ1 (for GCN4 motif binding) [11], OsBP-5, and OsEBP-89 [12], could directly bind and transactivate GBSSI expression. Besides, PBF can also bind to P-box located in the promoter of GBSSI, and thus, GBSSI expression can also be indirectly regulated by the direct binding of SERF1 to PBF [35]. Thus, the functions of the regulators during starch biosynthesis show spatiotemporal expression pattern specificities and require cooperation of multiple transcriptional factors.

\subsection{NAC}

Transcription factors of NAC (No Apical Meristem (NAM), ATAF1/2, cup-shaped cotyledon (CUC2)) represent one of the largest families in plants and are involved in the stress-induced response during development periods [29,62]. Yet, NACs of starch biosynthesis in cereal crops have relative conservation. For example, the maize NAC36 factor was identified based on the sequence homology of one reported rice gene [15]. However, the regulatory functions of NACs on starch synthesis have remained unclear until the recent reports of two TFs, ZmNAC128 and ZmNAC130.

ZmNAC128 and ZmNAC130 are specifically expressed in grain endosperm during the filling stage, and thus function in a spatiotemporal pattern [40]. These two NACs are not only regulators involved in starch synthesis, but also underly the regulatory mechanism of the synchronization of utilization on carbon metabolism [40]. ZmNAC128 and ZmNAC130 mediate starch synthesis in the endosperm [40] through binding to the ACGCAA motif in the promoters of Brittle 2 (BT2) and six other hypothetic genes, including Zpu1 (encoding Zea mays pullulanase-type starch debranching enzyme), GBSSI, Sh2 (for AGPase large subunit), $S S V$, ISA2, and SSIIa (Figure 2 and Table 1). In addition, two related NACs were identified by using the blasting of protein sequences in rice, which show the same phenomenon of selective pressure [40]. More importantly, syntenic alignments among divergent cereal genomes of some TFs have been shown throughout cereal evolution [63], but sequence similarity is not the whole story. For example, rice OsZIP58 [28] displays a similar function to maize O2 in the same mode [11], but its other highly orthologous (e.g., ZmbZIP60, ZmbZIP16, ZmbZIP17, ZmbZIP91) show great expression divergences in maize [33].

Recently, a novel NAC-type transcription factor was revealed to regulate starch biosynthesis in wheat. TaNAC019 is specifically expressed in endosperm, and functions during starch synthesis through the following ways [41]: (i) by direct binding to the protomers of glutenin-encoded genes, (ii) by mediation of the accumulation of storage proteins via regulated Wheat storage protein activator (TaSPA) expression and interaction with TaGAMyb, and (iii) by adjustment of the accumulation of starch by the regulation of SSIIa and Susy1. 


\section{4. $M Y B$}

As the widely distributed transcription factors, MYBs are vital for a variety of biological functions. However, the functional studies of MYBs on starch biosynthesis are still scarce in cereal crops. So far, only one MYB factor has been reported as a regulator during starch biosynthesis [16].

Although many MYBs, i.e., ZmMYB73, ZmMYB127, ZmMYB155, and ZmMYB14, seemed to play roles in starch biosynthesis, only ZmMYB14 [16] has been evidently identified to promote endosperm starch synthetic genes in maize (Figure 2). Besides, there are two points of contention remaining over ZmMYB14. One is that the binding motif of ZmBT1 for ZmMYB14 to function as a regulator of starch synthesis may not be through the MBSI site (TAACTG) but other sites or mechanisms, while another is that there are spatialtemporal differences between type I starch synthesis-associated genes and ZmMYB14 [16], which might be due to programmed cell death in endosperm. So, MYBs could function as important regulators related to starch biosynthesis, but more studies are required to reveal and decrypt the mechanisms of MYB factors during starch biosynthesis in cereal crops.

\subsection{DOF}

DOFs show endosperm-specific expression in the regulation of starch biosynthesis (Figure 2 and Table 1). Regulation of DOFs on starch biosynthesis is mainly reflected in seed development and germination [14]. Prolamin-box-binding factor (PBF) is one of the major endosperm-specific DOF family members. Nowadays, increasingly more cereal PBFs have been identified, including rice PBF (RPBF) [18], maize PBF (PBF) [10], barley PBF (BPBF) [18,44], and wheat PBF (WPBF) [45]. However, PBF usually performs regulatory roles in starch biosynthesis combined with other regulator factors, i.e., O2 [10], SERF [18], and MYB [36]. Nonetheless, there are diverse mechanisms that exist between seed development and seed germination. During rice grain development, the expression of $R P B F$ was negatively regulated by SERF1, displaying contrasting expression patterns [18,35], while during seed germination, the GAMyb-induced expression of RAmy $1 A$ was enhanced in the presence of RPBF $[64,65]$. One similar phenomenon has also been reported in Hordeum vulgare. GAMYB and BPBF in the developing endosperm activates the full Hor 2 expression controlled by the expression pattern of HvVP1 (VIVIPAROUS1), orthologous to ABI3 from Arabidopsis thaliana, whereas the activation of Amy6.4 in post-germinative reserve mobilization was mediated by GAMYB [36]. So, it seems that these processes share the regulation of AMY activity. Moreover, O2/PBF mediates the enzyme complex via the transactivation of PPDKs and SSIII during starch biosynthesis [10].

DOFs also mediated the synthesis of starch and seed storage proteins (SSPs) through recognition of the AAAG motif [66]. Several DOFs function as positive regulators to mediate starch accumulation during endosperm development. For example, three DOFs have been identified to regulate starch synthesis in maize, including ZmDOF1 [67], ZmDOF3 [16], and ZmDOF36 [43], which have different target genes (Figure 2). ZmDOF36 regulates ZmGBSSI and ZmISA1 through the combination with DOF core elements in their promoters both in vitro and in vivo [43], while ZmDOF3 could interact with the DOF core element of SSIIa [16].

\subsection{GRAS}

GRAS transcription factors are involved in plant growth and development processes, especially for endodermis specification [68]. Besides, GRAS is greatly associated with type I genes during endosperm starch synthesis in rice [14], but its function as a regulator for starch biosynthesis is still not understood in cereal crops.

One maize TF of GRAS, ZmGRAS20, plays regulatory roles in starch biosynthesis of rice endosperm [17]. Through transcriptome sequencing, ZmGRAS20 was selected and showed high expression both in developing maize grains [69] and in ZmGRAS20overexpressing rice seeds [17], but its specific expression parts were endosperm. Besides, ZmGRAS20 overexpression in rice leads to a chalkiness characteristic with an altered starch 
content and structure [17]. The molecular roles of GARS20 in starch synthesis require further studies.

\subsection{WRKY}

Sugar signaling in barley2 (SUSIBA2) is a plant-specific WRKY TF that regulates gene expression in the presence of sugar, thereby mediating the communication of sourcesink $[42,70]$ via a cis element of SURE (sugar responsive) in plant sugar signaling. SURE was first reported in potato [71], and was subsequently isolated from rice, barley, and wheat [70]. SUSIBA2 serves as a regulatory transcriptional factor to regulate sugar-responsive gene expression, i.e., isoamylase (ISO), and thereby mediates carbohydrate anabolism [70]. Interestingly, the heterologous expression of SUSIBA2 produced a rice variety with a high starch content but low methane emission [72], suggesting its important function in starch biosynthesis. In parallel, by using the antisense oligodeoxynucleotide (ODN) technology, one SUSIBA2 regulatory TF has been identified in barley [42]. SUSIBA2 binds to the SURE elements in the promoters of ISO1 and BEIIb, and confers tissue-specific sugar responsiveness [42,70]. Therefore, as a WRKY regulatory TF of sugar signaling, SUSIBA2 possesses some specific characteristics in cereals, and regulates starch biosynthesis through starch synthesis genes, i.e., ISO and BE.

\section{Other Regulators Directly Affecting Starch Biosynthesis}

Some regulatory factors cannot be listed in any of the above groups, and thus are included independently in this section (Figure 1), including FLOURY ENDOSPERM (FLO), $\mathrm{CO}_{2}$-responsive CONSTANS, CONSTANS-like, and time of chlorophyll a/b-binding protein1 (CRCT).

\subsection{Floury Endosperm}

FLOURY ENDOSPREM is named based on its well-recognized but viable endosperm phenotypes, which usually display a chalky and soft endosperm. So far, 16 rice floury mutants [73] and three maize floury mutants [74] have been identified. However, only rice FLO2 [75] and FLO7 [76], as well as ZmFloury3 [74] serve as regulators of starch biosynthesis but do not act as enzymes. Although all of them play key roles in the regulation of starch formation, and are also responsible for aberrant seeds with reduced grain quality [74-76], their functioning models vary.

FLO2 acts as a regulatory protein that controls the biosynthesis of seed storage substances, possibly through its tetratricopeptide repeat (TPR) motifs for protein-protein interactions [75]. At least two proteins have been reported that interact with FLO2 during starch synthesis (Figure 1). One basic helix-loop-helix (bHLH) protein may interact with FLO2 to modulate the expression of starch biosynthesis-associated nuclear genes (SBANGs) [75]. Subsequently, the FLO2-interacting cupin domain protein 1 (FLOC1) was reported to interact with the TPR motif of FLO2 to maintain fertility and seed quality in rice [77], even though they are supposed to have different functions.

FLO7 prefers to specifically function in the endosperm periphery, and harbors two essential domains of an $N$-terminal transit peptide and an unknown function 1338 (DUF1338), during starch synthesis and amyloplast development [76].

Floury3 (named FL3), a plant AT-rich sequence and zinc-binding (PLATZ) protein, acts as a specific regulator in maize starchy endosperm cells [74]. FL3 plays vital roles in endosperms during seed-filling periods through interactions with RNA polymerase III subunit 53 (RPC53) and transcription factor class C 1 (TFC1), which are two critical factors of the RNA polymerase III (RNAPIII) transcription complex [74]. Interestingly, FL3 was regulated by genomic imprinting [74], and thus, its mutation caused a semidominantnegative mutant. 


\section{2. $C R C T$}

The CRCT protein has been reported to be a regulator of starch biosynthesis in rice but does not seem to belong to a zinc finger motif [78], and cannot be listed in any of the above groups. Thus, here, CRCT is grouped independently. The expression of OsCRCT displays diurnal oscillation and is mainly focused on the vegetative organs. Therefore, OsCRCT serves as a positive regulator of several starch biosynthetic genes, including AGPS1, AGPL1, Glc-6-phosphate translocator2 (GPT2), plastidial $\alpha$-glucan phosphorylase1 (Pho1), and BEIIa, and contributes to starch biosynthesis in rice leaves [78]. The effects of OsCRCT on the storage of starch are unclear so far. However, the use of plants overexpressing OsCRCT is a potential approach to improve yields for food and biofuel [78], depending on the increased contents of starch derived from enhanced synthesis of starch instead of the defects of starch breakdown or translocation.

\section{Regulators Indirectly Mediating Starch Biosynthesis}

Aside from the direct regulators of starch biosynthesis, many other factors also participate in the regulation of starch synthesis, partially through the post-transcriptional regulation of TFs, i.e., micro RNAs (miRNAs), or via regulators of the formation of the upstream precursors and/or downstream products of starch.

\section{1. miRNAs}

miRNAs can negatively mediate gene expression at the post-transcription levels [79], and have regulatory roles in plant development, e.g., hormone signaling, stress responses, and so on $[80,81]$. miRNAs have been reported to regulate starch accumulation during grain filling in cereal crops, including rice [82], wheat [83], and maize [84,85]. In rice, miR167 regulates seed formation through a confirmed pathway of auxin-miR167-ARF8OsGH3.2 (encoding Indole-3-acetic acid-amido synthetase) [18,82]. Yet, OsGH3.2 seems to have no direct correlation with starch biosynthesis, but the target mRNAs of many sucrose-induced miRNAs, i.e., miR159, miR397, miR160, miR529, miR166, miR528, miR167, miR171, miR398, and miR827, are characterized as transcription factors [84], including AP2/ERF, ARF, GRAS, MYB, NAC, and WRKY in maize. Most of these TFs are involved in endosperm starch biosynthesis, suggesting that the sucrose-induced regulation of starch synthetic genes is possibly through miRNAs. However, the related signaling pathway among them remains largely unknown.

\subsection{TFs Involved in the Regulation of Sugars and Proteins}

Some transcription factors have been reported to mediate starch accumulation in cereal endosperms, but they participate in regulation via control of the synthesis of the downstream and/or upstream products of starch, i.e., sugar and proteins, instead of directly regulating starch synthesis. Here, we mainly concentrate on some of them (Table 2), including bZIPs, NAC, DOF, MADS, and basic helix-loop-helix (bHLH). 
Table 2. Regulators indirectly affecting starch biosynthesis of cereal crops.

\begin{tabular}{|c|c|c|c|c|}
\hline TF & Binding Domains & Target Genes & $\begin{array}{c}\text { Specific Expressed } \\
\text { Tissues }\end{array}$ & References \\
\hline \multicolumn{5}{|c|}{ Oryza sativa L. } \\
\hline RISBZ1/bZIP58 & $\begin{array}{l}\text { TCCACGT(a/c)R(a/t) } \\
\text { and GATGYRTGG }\end{array}$ & $\mathrm{O} 2$ & Endosperm & [28] \\
\hline & & Zea mays $\mathrm{L}$. & & \\
\hline ZmbZIP22 & ACAGCTCA & $27-k D a \gamma$-zein & Endosperm & [86] \\
\hline $\mathrm{O} 2$ & GA/TGAPyPuTGPu & PPDK & & {$[9,22,23]$} \\
\hline $\mathrm{O} 2$ & TCCACGTAGA & $22 \mathrm{kDa}$ zein & All types of tissues & {$[9,22,23]$} \\
\hline OHP1 & O2-likebox (TTTACGT) & $\begin{array}{c}27-k D a \gamma-z e i n \text { and } 22-k D a \\
\alpha \text {-zein }\end{array}$ & & [87] \\
\hline OHP2 & O2-likebox (TTTACGT) & zein & & [87] \\
\hline ZmABI19 & RY & $\begin{array}{l}\text { O2, PBF1, ZmbZIP22, } \\
\text { NAC130, O11 }\end{array}$ & Endosperm and embryo & [88] \\
\hline ZmNAC128 & ACGCAA & $16-k D a \gamma$-zein & Endosperm & [40] \\
\hline ZmNAC130 & ACGCAA & $16-k D a \gamma$-zein & Endosperm & [40] \\
\hline ZmMADS47 & CATGT & $\alpha$-zein and $50-k D a$-zein & Endosperm & [45] \\
\hline PBF/DOF13 & TGTAAAG & $27-k D \gamma$ - and $22-k D \alpha$-zein & Endosperm & [10] \\
\hline DOF1 & & $\begin{array}{c}\gamma \text {-zein } \\
\text { Triticum aestizum }\end{array}$ & Endosperm & [64] \\
\hline TaNAC019 & & SPA, GaMyb, Glutenin & Endosperm & [41] \\
\hline
\end{tabular}

\subsection{1. bZIP}

Aside from direct regulation of starch synthetic enzymes, some bZIPs are also involved in the regulation of starch synthesis via indirect ways (Table 2). For example, $\mathrm{O} 2$ can regulate the gene expression of $\alpha$ - and $\beta$-zein [23], b-32 [21], and pyruvate orthophosphate dikinase 1 (PPDK1) $[10,22]$ via recognition of the $\mathrm{O} 2 \mathrm{box}, \mathrm{GA} / \mathrm{TGAPyPuTGPu}$, and TCCACGTAGA sequences in their promoters, respectively. Moreover, two heterodimerizing proteins of $\mathrm{O} 2$, OHP1 and OHP2, can regulate the synthesis of 27-kDa $\gamma$-zein and 22-kDa $\alpha$-zein $[86,87]$ through the recognition of the O2-like motif in the promoters of the target genes. O2, PBF, and OHP1/OHP2 can jointly form a complex with ZmbZIP22 [86] to combine with the ACAGCTCA motif in the promoter of $\gamma$-zein (27-kDa) [87]. Besides, the interaction of O2 with ZmMADS47, an MADS box-containing TF [89], is essential to activate $\alpha$-zein and $50-\mathrm{kDa} \gamma$-zein through the binding of the CATGT motif in their promoters.

\subsubsection{AP2/ERF}

Recently, one B3 domain-containing AP2/ERF transcriptional factor, ZmABI19 [88], was well documented to mediate starch synthesis via binding with RY through the regulation of cooperated expression of O2, PBF1, ZmbZIP22, NAC130, and O11.

\subsubsection{NAC}

Regulation of NAC on starch synthetic enzymes is often accompanied with a simultaneous regulation of storage protein synthesis-associated genes (Table 2). Although ZmNAC128 and ZmNAC130 have been well documented to regulate several starch biosynthetic genes, they can also bind with the motif of ACGCAA to activate the expression of 16-kDa $\gamma$-zein genes [40]. However, these two NAC factors [40] do not dimerize with each other but are functionally redundant for starch and protein accumulation. A similar phenomenon was also found in wheat [41]. TaNAC019 [41] has been reported to directly bind to the promoters of glutenin-encoded genes and be involved in the accumulation of starch and proteins. Therefore, the regulation of starch biosynthesis is not independent but prefers to act synergistically with other metabolic processes, i.e., protein synthesis. 


\subsubsection{DOF}

Some DOF TFs have similar effects on the regulation of starch synthesis. PBF specifically binds with P-box (TGTAAAG) to mediate the synthesis of proteins (Table 2), i.e., $\alpha$-zein and $\gamma$-zein [64]. PBF can also interact with O2, PBF, and OHP1/OHP2 to form a complex with ZmbZIP22 [86] to regulate the expression of 27-kDa $\gamma$-zein [85]. Therefore, the correlation of PBF and other factors is greatly related to seed size, vigor, and germination. Moreover, other DOFs mediate seed storage proteins (SSPs) through recognition of the AAAG motif [67] during seed development. DOF1 promotes the upregulated expression of $\gamma$-zein [64], while ZmDOF3 [16] can bind to the Nkd1 (naked endosperm 1) promoter to regulate aleurone cell differentiation.

\subsubsection{MADS}

MADS-box transcription factors have attracted increasingly more attention in the studies of seed development [68,90]. For example, ZmMADS1, a typical MADS-box transcription factor, regulates sugar synthesis-associated genes, and functions to affect the endosperm characteristics of maize seeds as well as in resistance to drought stress [45]. A similar phenomenon also exists in rice endosperm $[45,90]$. This is largely dependent on the similar adjustment mechanism of ZmMADS1, which shows enhanced expression of starch biosynthetic genes, i.e., GBSSI, in mature seeds. Another MADS TF, ZmMADS47, through the interactions with OPAQUE2, directly regulates prolamin in maize [89]. Interestingly, in rice, OsMADS29 has been explored to produce shrunken seeds, but the underlying mechanism prefers programmed cell deaths (PCDs) [91]. However, ZmES22, one of the MADS TFs, has been documented to negatively regulate endosperm starch accumulation in rice via direct downregulation of the expression of OsGIF1 during grain filling stages [92]. Thus, the regulation of MADS TFs on starch biosynthesis depends on various ways, i.e., (i) by adjusting sugars, (ii) by mediating prolamins, (iii) and through PCDs, and so on.

\subsection{6. bHLH}

TFs of basic helix-loop-helix act as important regulators of starch synthesis during seed formation $[93,94]$. For example, maize opaque11 showed endosperm-specific expression and participated in the regulation of NKD2 and ZmDOF3 during endosperm development. Besides, it is also involved in the regulation of nutrient and carbohydrate metabolism via $\mathrm{O} 2$ and $\mathrm{PBF}$, as well as in response to environmental stresses. Thus, OPAQUE11 may work as the focus hub in the regulatory network during seed formation [94].

ZHOUP1 (ZOU) is involved in the seed formation of angiosperm plants, i.e., Arabidopsis thaliana [95,96] and maize [93]. ZmZOU is specifically expressed in endosperm, especially during the filling periods [94]. Similar interaction mechanisms for seed development are also found in maize [93] and in Arabidopsis [96,97], via the formation of functional heterodimers. However, it is essential for ZmZOU to tightly bind with its specific ZmICEa in the formation of grain filling. Thus, this seems to be unique for monocotyledon plants. All in all, ZHOUP1 does not directly affect starch biosynthesis but plays vital roles in the formation of endosperm and embryo.

\section{Conclusions}

Starch was and remains an essential commodity in food and non-food industries. Cereal seeds provide a great account of starch production, and thereby, starch synthesis and its regulation in seed endosperm have been investigated by researchers of breeding. The enzymes involved in starch synthesis have been well identified in cereals, but, until now, the regulatory mechanism underlying starch synthesis has not been fully understood, especially regarding the regulators on starch synthetic genes. As the key regulators mediating gene expression, the working models of transcriptional factors perform complicated networks during starch biosynthesis (Figure 1), and mainly depend on (i) the activation of different environmental factors; (ii) interaction with various factors, including other TFs; 
(iii) mediation of endogenous hormones; (iv) regulation of multiple genes by one TF; and (v) regulation of single gene by multiple TFs, and so on.

The race between the increasing starch demand and the shrinking arable land has resulted in the urgency to further understand starch biosynthesis and its regulation, which is vital to produce a rational design of agronomic traits and more and better polymers with biotechnological approaches. Besides, improved cereal grain quality is also essential to consumers; however, the formation of seed quality is a highly complex process. These processes are largely adjusted with various regulators, which perform precision guidance on the cooperation of starch synthesis-related proteins and lipids. Therefore, it is insufficient for the selection of any single trait in crop breeding.

Currently, the main application of cereal starch is to feed the increasing human population as a vital food source, and thus, high yields of cereals or improvement of states of starch shortage are still the key breeding targets. However, the enzymes involved in starch synthesis have been well identified in cereals, but the efforts to improve starch synthesis have failed using the simplistic one-enzyme strategy [98]. This was because precise cooperation of many modules was required in the process of starch synthesis, including enzymes, transporters, and regulators, i.e., TFs. Therefore, exploring more TFs and cis-elements is one potential strategy to mediate starch synthesis, especially for cells or tissues that lack starch $[98,99]$. However, compared with the abundant regulators that have been well identified in Arabidopsis, only dozens of regulators, especially for TFs, have been reported in cereal crops. Thus, the traditional mutagenesis technology, combined with advanced gene editing technology (i.e., CRISPR-Cas9), is a commonly used way to explore novel TFs, whose binding motifs can be determined with DAP-seq [100] and/or Chip-seq [101] technologies.

Besides, the building of regulatory networks can also help to design a rational strategy to improve starch biosynthesis. In order to achieve this, the selection and visualization of homogenized cells is key to the transcriptomic technologies [98] with the ancillary applications of fluorescent microscopy [102]. Recently, the successful application of single-cell RNA sequencing (scRNA-seq) in plants [103] provides another selective method to clarify the expression patterns of genes involved in starch synthesis, although it is technically challenging and expensive. Moreover, although still being controversial in legislations and ethics, the overexpression of genes via transgenic plants could serve as an effective and efficient way to improve starch synthesis, including the heterologous expression of genes derived from other cereals [71] and Homo sapiens [104]. The heterologous expression of wheat SUSIBA2 in rice [71] produced a rice variety with high starch but low methane emission. Interestingly, recently, the successful introduction of FTO, one specific Homo sapiens gene associated with obesity and fat mass, into rice and potato largely increased the productivity and biomass [104]. Since FTO naturally exists in the human genome [104], it is feasible to introduce similar genes into cereals to improve starch synthesis.

Collectively, this review summarized the regulators underlying starch synthesis in cereal crops, and will help to provide potential applications in crop breeding and engineering efforts.

Author Contributions: Conceptualization, R.L. and H.Z.; writing—original draft preparation, R.L. and Y.T.; writing-review and editing, H.Z.; funding acquisition, R.L. and H.Z. All authors have read and agreed to the published version of the manuscript.

Funding: This work is funded by a grant from the Central Public-interest Scientific Institution Basal Research Fund (CPSIBRF-CNRRI-202105), Natural Foundation of Anhui Province (1908085QC103), and the Open Project Program of State Key Laboratory of Rice Biology (20200104).

Institutional Review Board Statement: Not applicable.

Informed Consent Statement: Not applicable.

Data Availability Statement: All data generated or analyzed during this study are included in this published article. 
Acknowledgments: We thank Yafang Shao and Huizhi Shen (Naitional Rice Research Institute) for the help with language revision.

Conflicts of Interest: The authors declare no conflict of interest.

\section{References}

1. Geigenberger, P. Regulation of starch biosynthesis in response to a fluctuating environment. Plant Physiol. 2011, 155, 1566-1577. [CrossRef] [PubMed]

2. Zeeman, S.C.; Kossmann, J.; Smith, A.M. Starch: Its metabolism, evolution, and biotechnological modification in plants. Annu. Rev. Plant Biol. 2010, 61, 209-234. [CrossRef] [PubMed]

3. Sulpice, R.; Pyl, E.T.; Ishihara, H.; Trenkamp, S.; Steinfath, M.; Witucka-Wall, H.; Gibon, Y.; Usadel, B.; Poree, F.; Piques, M.C. Starch as a major integrator in the regulation of plant growth. Proc. Natl. Acad. Sci. USA 2009, 106, 10348-10353. [CrossRef] [PubMed]

4. Geigenberger, P.; Stitt, M.; Fernie, A.R. Metabolic control analysis and regulation of the conversion of sucrose to starch in growing potato tubers. Plant Cell Environ. 2010, 27, 655-673. [CrossRef]

5. Bahaji, A.; Li, J.; Sánchez-López, Á.M.; Baroja-Fernández, E.; Muñoz, F.J.; Ovecka, M.; Almagro, G.; Montero, M.; Ezquer, I.; Etxeberria, E.; et al. Starch biosynthesis, its regulation and biotechnological approaches to improve crop yields. Biotechnol. Adv. 2014, 32, 87-106. [CrossRef]

6. Sabelli, P.A.; Larkins, B.A. The development of endosperm in grasses. Plant Physiol. 2009, 149, 14-26. [CrossRef] [PubMed]

7. Stitt, M.; Zeeman, S.C. Starch turnover: Pathways, regulation and role in growth. Curr. Opin. Plant Biol. 2012, 15, 282-292. [CrossRef]

8. Li, R.; Jiang, M.; Zheng, W.; Zhang, H. GUN4-mediated tetrapyrrole metabolites regulates starch biosynthesis during early seed development in rice. J. Cereal Sci. 2021, 101, 103317. [CrossRef]

9. Stower, H. Gene regulation: Resolving transcription factor binding. Nat. Rev. Genet. 2011, 13, 71. [CrossRef]

10. Zhang, Z.; Zheng, X.; Yang, J.; Messing, J.; Wu, Y. Maize endosperm-specific transcription factors O2 and PBF network the regulation of protein and starch synthesis. Proc. Natl. Acad. Sci. USA 2016, 113, 10842-10847. [CrossRef]

11. Wang, J.; Xu, H.; Zhu, Y.; Liu, Q.; Cai, X. OsbZIP58, a basic leucine zipper transcription factor, regulates starch biosynthesis in rice endosperm. J. Exp. Bot. 2013, 64, 3453-3466. [CrossRef]

12. Zhu, Y.; Cai, X.L.; Wang, Z.Y.; Hong, M.M. An interaction between a MYC protein and an EREBP protein is involved in transcriptional regulation of the rice Wx gene. J. Biol. Chem. 2003, 278, 47803-47811. [CrossRef]

13. Liu, G.; Wu, Y.; Xu, M.; Gao, T.; Wang, P.; Wang, L.; Guo, T.; Kang, G. Virus-induced gene silencing identifies an important role of the TaRSR1 Transcription factor in starch synthesis in bread wheat. Int. J. Mol. Sci. 2016, 17, 1557. [CrossRef]

14. Fu, F.F.; Xue, H.W. Coexpression analysis identifies rice starch regulator1, a rice AP2/EREBP family transcription factor, as a novel rice starch biosynthesis regulator. Plant Physiol. 2010, 154, 927-938. [CrossRef] [PubMed]

15. Zhang, J.; Chen, J.; Yi, Q.; Hu, Y.; Liu, H.; Liu, Y. Novel role of ZmaNAC36 in co-expression of starch synthetic genes in maize endosperm. Plant Mol. Biol. 2014, 84, 359-369. [CrossRef] [PubMed]

16. Xiao, Q.; Wang, Y.; Du, J.; Li, H.; Wei, B.; Wang, Y.; Li, Y.; Yu, G.; Liu, H.; Zhang, J.; et al. ZmMYB14 is an important transcription factor involved in the regulation of the activity of the ZmBT1 promoter in starch biosynthesis in maize. FEBS J. 2017, 284, 3079-3099. [CrossRef]

17. Cai, H.; Chen, Y.; Zhang, M.; Cai, R.; Cheng, B.; Ma, Q.; Zhao, Y. A novel GRAS transcription factor, ZmGRAS20, regulates starch biosynthesis in rice endosperm. Physiol. Mol. Biol. Plants 2017, 23, 143-154. [CrossRef] [PubMed]

18. Kawakatsu, T.; Yamamoto, M.P.; Touno, S.M.; Yasuda, H.; Takaiwa, F. Compensation and interaction between RISBZ1 and RPBF during grain filling in rice. Plant J. 2009, 59, 908-920. [CrossRef]

19. Mena, M.; Vicente-Carbajosa, J.; Schmidt, R.J.; Carbonero, P. An endosperm-specific DOF protein from barley, highly conserved in wheat, binds to and activates transcription from the prolamin-box of a native B-hordein promoter in barley endosperm. Plant $J$. 1998, 16, 53-62. [CrossRef] [PubMed]

20. Ohdan, T.; Francisco, P.B., Jr.; Sawada, T.; Hirose, T.; Terao, T.; Satoh, H.; Nakamura, Y. Expression profiling of genes involved in starch synthesis in sink and source organs of rice. J. Exp. Bot. 2005, 56, 3229-3244. [CrossRef]

21. Mertz, E.T.; Bates, L.S.; Nelson, O.E. Mutant gene that changes protein composition and increases lysine content of maize endosperm. Science 1964, 145, 279-280. [CrossRef] [PubMed]

22. Lohmer, S.; Maddaloni, M.; Motto, M.; Di Fonzo, N.; Hartings, H.; Salamini, F.; Thompson, R.D. The maize regulatory locus Opaque-2 encodes a DNA-binding protein which activates the transcription of the b-32 gene. EMBO J. 1991, 10, 617. [CrossRef] [PubMed]

23. Schmidt, R.J.; Ketudat, M.; Aukerman, M.J.; Hoschek, G. Opaque-2 is a transcriptional activator that recognizes a specific target site in 22-kD zein genes. Plant Cell 1992, 4, 689-700. [PubMed]

24. Izawa, T.; Foster, R.; Nakajima, M.; Shimamoto, K.; Chua, N.H. The rice bZIP transcriptional activator RITA-1 is highly expressed during seed development. Plant Cell 1994, 6, 1277-1287.

25. Vicente-Carbajosa, J.; Onate, L.; Lara, P.; Diaz, I.; Carbonero, P. Barley BLZ1: A bZIP transcriptional activator that interacts with endosperm-specific gene promoters. Plant J. 1998, 13, 629-640. 
26. Kumar, P.; Mishra, A.; Sharma, H.; Sharma, D.; Rahim, M.S.; Sharma, M.; Parveen, A.; Jain, P.; Verma, S.K.; Rishi, V.; et al. Pivotal role of bZIPs in amylose biosynthesis by genome survey and transcriptome analysis in wheat (Triticum aestivum L.) mutants. Sci. Rep. 2018, 8, 17240. [CrossRef] [PubMed]

27. Song, Y.; Luo, G.; Shen, L.; Yu, K.; Yang, W.; Li, X.; Sun, J.; Zhan, K.; Cui, D.; Liu, D.; et al. TubZIP28, a novel bZIP family transcription factor from Triticum urartu and TabZIP28, its homolog from Triticum aestivum enhance starch synthesis in wheat. New Phytol. 2020, 226, 1384-1398. [CrossRef]

28. Onodera, Y.; Suzuki, A.; Wu, C.; Washida, H.; Takaiwa, F. A rice functional transcriptional activator, RISBZ1, responsible for endosperm-specific expression of storage protein genes through GCN4 motif. J. Biol. Chem. 2001, 276, 14139-14152. [CrossRef]

29. Kim, J.S.; Chae, S.; Jun, K.M.; Pahk, Y.M.; Lee, T.H.; Chung, P.J.; Kim, Y.K.; Nahm, B.H. Genome-wide identification of grain filling genes regulated by the OsSMF1 transcription factor in rice. Rice 2017, 10, 16. [CrossRef]

30. Yamamoto, M.P.; Onodera, Y.; Touno, S.M.; Takaiwa, F. Synergism between RPBF Dof and RISBZ1 bZIP activators in the regulation of rice seed expression genes. Plant Physiol. 2006, 141, 1694-1707. [CrossRef]

31. Kawakatsu, T.; Takaiwa, F. Differences in transcriptional regulatory mechanisms functioning for free lysine content and seed storage protein accumulation in rice grain. Plant Cell Physiol. 2010, 51, 1964-1974. [CrossRef]

32. Cai, Y.; Xie, D.L.; Wang, Z.Y.; Hong, M.M. Interaction of rice bZIP protein REB with the $5^{\prime}$-upstream region of both rice sbe1 gene and waxy gene. Chin. Sci. Bull. 2002, 47,310-314. [CrossRef]

33. Chen, J.; Yi, Q.; Cao, Y.; Wei, B.; Zheng, L.; Xiao, Q.; Xie, Y.; Gu, Y.; Li, Y.; Huang, H.; et al. ZmbZIP91 regulates expression of starch synthesis-related genes by binding to ACTCAT elements in their promoters. J. Exp. Bot. 2016, 67, 1327-1338. [CrossRef] [PubMed]

34. Wuriyanghan, H.; Zhang, B.; Cao, W.H.; Ma, B.; Lei, G.; Liu, Y.F. The ethylene receptor etr2 delays floral transition and affects starch accumulation in rice. Plant Cell 2009, 21, 1473-1494. [CrossRef] [PubMed]

35. Schmidt, R.; Schippers, J.H.M.; Mieulet, D.; Watanabe, M.; Hoefgen, R.; Guiderdoni, E.; Mueller-Roeber, B. SALT-RESPONSIVE ERF1 is a negative regulator of grain filing and gibberellin-mediated seedling establishment in rice. Mol. Plant 2014, 7, 401-421. [CrossRef] [PubMed]

36. Abraham, Z.; Iglesias-Fernández, R.; Martínez, M.; Rubio-Somoza, I.; Díaz, I.; Carbonero, P.; Vicente-Carbajosa, J. A developmental switch of gene expression in the barley seed mediated by HvVP1 (Viviparous-1) and HvGAMYB interactions. Plant Physiol. 2016, 170, 2146-2158. [CrossRef] [PubMed]

37. Hu, Y.F.; Li, Y.P.; Zhang, J.; Liu, H.; Tian, M.; Huang, Y. Binding of ABI4 to a CACCG motif mediates the ABA-induced expression of the ZmSSI gene in maize (Zea mays L.) endosperm. J. Exp. Bot. 2012, 63, 5979-5989. [CrossRef]

38. Fukao, T.; Xu, K.; Ronald, P.; Bailey-Serres, J. A variable cluster of ethylene response factor-like genes regulates metabolic and developmental acclimation responses to submergence in rice. Plant Cell 2006, 18, 2021-2034. [CrossRef]

39. Li, H.; Xiao, Q.; Zhang, C.; Du, J.; Li, X.; Huang, H.; Wei, B.; Li, Y.; Yu, G.; Liu, H.; et al. Identification and characterization of transcription factor ZmEREB94 involved in starch synthesis in maize. J. Plant Physiol. 2017, 216, 11-16. [CrossRef]

40. Zhang, Z.; Dong, J.; Chen, J.; Wu, Y.; Messing, J. NAC-type transcription factors regulate accumulation of starch and protein in maize seeds. Proc. Natl. Acad. Sci. USA 2019, 116, 11223-11228. [CrossRef]

41. Gao, Y.; An, K.; Guo, W.; Chen, Y.; Zhang, R.; Zhang, X.; Chang, S.; Rossi, V.; Jin, F.; Cao, X.; et al. The endosperm-specific transcription factor TaNAC019 regulates glutenin and starch accumulation and its elite allele improves wheat gain quality. Plant Cell 2021, 33, 603-622. [CrossRef]

42. Sun, C.; Höglund, A.S.; Olsson, H.; Mangelsen, E.; Jansson, C. Antisense oligodeoxynucleotide inhibition as a potent strategy in plant biology: Identification of SUSIBA2 as a transcriptional activator in plant sugar signaling. Plant J. 2005, 44, 128-138. [CrossRef] [PubMed]

43. Wu, J.; Chen, L.; Chen, M.; Zhou, W.; Dong, Q.; Jiang, H.; Cheng, B. The DOF-Domain Transcription Factor ZmDOF36 Positively Regulates Starch Synthesis in Transgenic Maize. Front Plant Sci. 2019, 10, 465. [CrossRef]

44. Diaz, I.; Vicente-Carbajosa, J.; Abraham, Z.; Martínez, M.; Isabel-La Moneda, I.; Carbonero, P. The GAMYB protein from barley interacts with the DOF transcription factor BPBF and activates endosperm-specific genes during seed development. Plant J. 2002, 29, 453-464. [CrossRef] [PubMed]

45. Dong, Q.; Wang, F.; Kong, J.; Xu, Q.; Li, T.; Chen, L.; Chen, H.; Jiang, H.; Li, C.; Cheng, B. Functional analysis of ZmMADS1a reveals its role in regulating starch biosynthesis in maize endosperm. Sci. Rep. 2019, 9, 3253. [CrossRef] [PubMed]

46. Chen, J.; Huang, B.; Li, Y.P.; Du, H.; Gu, Y.; Liu, H.M.; Zhang, J.J.; Huang, Y.B. Synergistic influence of sucrose and abscisic acid on the genes involved in starch synthesis in maize endosperm. Carbohydr. Res. 2011, 346, 1684-1691. [CrossRef] [PubMed]

47. Xie, Y.L. AP2/EREBP: A special transcription factor family in plants. J. Qinghai Norm. Univ. 2006, 3, 80-83, (In Chinese with English abstract).

48. Acevedo-Hernández, G.J.; León, P.; Herrera-Estrella, L.R. Sugar and ABA responsiveness of a minimal RBCS light-responsive unit is mediated by direct binding of ABI4. Plant J. 2005, 43, 506-519. [CrossRef]

49. Bai, X.F.; Cai, Y.P.; Nie, F. Relationship between abscisic acid and grain filling of rice and wheat. Plant Physiol. Commun. 1989, 25, 40-41.

50. Zhu, G.H.; Ye, N.H.; Yang, J.C.; Peng, X.X.; Zhang, J.H. Regulation of expression of starch synthesis genes by ethylene and ABA in relation to the development of rice inferior and superior spikelets. J. Exp. Bot. 2011, 62, 3907-3916. [CrossRef] 
51. Seiler, C.; Harshavardhan, V.T.; Rajesh, K.; Reddy, P.S.; Strickert, M.; Rolletschek, H.; Scholz, U.; Wobus, U.; Sreenivasulu, N. ABA biosynthesis and degradation contributing to ABA homeostasis during barley seed development under control and terminal drought-stress conditions. J. Exp. Bot. 2011, 62, 2615-2632. [CrossRef]

52. Huang, H.; Xie, S.; Xiao, Q.; Wei, B.; Zheng, L.; Wang, Y.; Cao, Y.; Zhang, X.; Long, T.; Li, Y.; et al. Sucrose and ABA regulate starch biosynthesis in maize through a novel transcription factor, ZmEREB156. Sci. Rep. 2016, 6, 27590. [CrossRef]

53. Chen, Z.; Huang, J.; Muttucumaru, N.; Powers, S.J.; Halford, N.G. Expression analysis of abscisic acid (ABA) and metabolic signalling factors in developing endosperm and embryo of barley. J. Cereal Sci. 2013, 58, 255-262. [CrossRef] [PubMed]

54. Nambara, E.; Okamoto, M.; Tatematsu, K.; Yano, R.; Seo, M.; Kamiya, Y. Abscisic acid and the control of seed dormany and germination. Seed Sci. Res. 2010, 20, 55-67. [CrossRef]

55. McCarty, D.R.; Carson, C.B.; Stinard, P.S.; Robertson, D.S. Molecular analysis of viviparous-1: An abscisic acid-insensitive mutant of maize. Plant Cell 1989, 1, 523-532. [CrossRef]

56. McCarty, D.R.; Hattori, T.; Carson, C.B.; Vasil, V.; Lazar, M.; Vasil, I.K. The Viviparous-1 developmental gene of maize encodes a novel transcriptional activator. Cell 1991, 66, 895-905. [CrossRef]

57. Niu, X.; Helentjaris, T.; Bate, N.J. Maize ABI4 binds coupling element1 in abscisic acid and sugar response genes. Plant Cell 2002, 14, 2565-2575. [CrossRef] [PubMed]

58. Rook, F.; Hadingham, S.A.; Li, Y.; Bevan, M.W. Sugar and ABA response pathways and the control of gene expression. Plant Cell Environ. 2006, 29, 426-434. [CrossRef]

59. Koussevitzky, S.; Nott, A.; Mockler, T.C.; Hong, F.; Sachetto-Martins, G.; Surpin, M.; Lim, J.; Mittler, R.; Chory, J. Signals from chloroplasts converge to regulate nuclear gene expression. Science 2007, 316, 715-719. [CrossRef]

60. Gubler, F.; Kalla, R.; Roberts, J.K.; Jacobsen, J.V. Gibberellin-regulated expression of a myb gene in barley aleurone cells: Evidence for Myb transactivation of a high-pI a-amylase gene promoter. Plant Cell 1995, 7, 1879-1891. [CrossRef]

61. Gubler, F.; Raventos, D.; Keys, M.; Watts, R.; Mundy, J.; Jacobsen, J.V. Target genes and regulatory domains of the GAMYB transcriptional activator in cereal aleurone. Plant J. 1999, 17, 1-9. [CrossRef]

62. Olsen, A.N.; Ernst, H.A.; Leggio, L.L.; Skriver, K. NAC transcription factors: Structurally distinct, functionally diverse. Trends Plant Sci. 2005, 10, 79-87. [CrossRef] [PubMed]

63. $\mathrm{Xu}, \mathrm{J} . \mathrm{H}$.; Messing, J. Diverged copies of the seed regulatory Opaque-2 gene by a segment duplication in the progenitor genome of rice, sorghum, and maize. Mol. Plant 2008, 1, 760-769. [CrossRef] [PubMed]

64. Washio, K. Functional dissections between GAMYB and Dof transcription factors suggest a role for protein-protein associations in the gibberellin-mediated expression of the RAmy1A gene in the rice aleurone. Plant Physiol. 2003, 133, 850-863. [CrossRef]

65. Washio, K.; Morikawa, M. Common mechanisms regulating expression of rice aleurone genes that contribute to the primary response for gibberellin. Biochim. Biophys. Acta 2006, 1759, 478-490. [CrossRef]

66. Yanagisawa, S. Dof domain proteins: Plant-specific transcription factors associated with diverse phenomena unique to plants. Plant Cell Physiol. 2004, 45, 386-391. [CrossRef] [PubMed]

67. Marzabal, P.; Gas, E.; Fontanet, P.; Vicente-Carbajosa, J.; Torrent, M.; Ludevid, M.D. The maize Dof protein PBF activates transcription of gammazein during maize seed development. Plant Mol. Biol. 2008, 67, 441-454. [CrossRef]

68. Wang, X.L.; Chen, Y.P.; De-yue, Y. Expression of the MADS-Box gene GmAGL15 in seed development of soybean: Expression the MADS-Box gene GmAGL15 in seed development of Soybean. Acta Agron. Sin. 2008, 34, 330-332. [CrossRef]

69. Li, G.S.; Wang, D.F.; Yang, R.L.; Logan, K.; Chen, H.; Zhang, S.; Skaggs, M.I.; Lloyd, A.; Burnett, W.J.; Laurie, J.D.; et al. Temporal patterns of gene expression in developing maize endosperm identified through transcriptome sequencing. Proc. Natl. Acad. Sci. USA 2014, 111, 7582-7587. [CrossRef] [PubMed]

70. Sun, C.; Palmqvist, S.; Olsson, H.; Boren, M.; Ahlandsberg, S.; Jansson, C. A novel WRKY transcription factor, SUSIBA2, participate in sugar signaling in Barley by binding to the sugar-responsive elements of the ISO1 promoter. Plant Cell 2003, 15, 2076-2092. [CrossRef] [PubMed]

71. Grierson, C.; Du, J.S.; de Torres Zabala, M.; Beggs, K.; Smith, C.; Holdsworth, M.; Bevan, M.W. Separate cis sequences and trans factors direct metabolic and developmental regulation of a potato tuber storage protein gene. Plant J. 1994, 5, 815-826. [CrossRef]

72. Su, J.; Hu, C.; Yan, X.; Jin, Y.; Chen, Z.; Guan, Q.; Wang, Y.; Zhong, D.; Jansson, C.; Wang, F.; et al. Expression of barley SUSIBA2 transcription factor yields high-starch low-methane rice. Nature 2015, 523, 602-606. [CrossRef]

73. Teng, X.; Zhong, M.; Zhu, X.; Wang, C.; Ren, Y.; Wang, Y.; Zhang, H.; Jiang, L.; Wang, D.; Hao, Y.; et al. FLOURY ENDOSPERM16 encoding a NAD-dependent cytosolic malate dehydrogenase plays an important role in starch synthesis and seed development in rice. Plant Biotechnol. J. 2019, 17, 1914-1927. [CrossRef] [PubMed]

74. Li, Q.; Wang, J.; Ye, J.; Zheng, X.; Xiang, X.; Li, C.; Fu, M.; Wang, Q.; Zhang, Z.; Wu, Y. The maize imprinted gene Floury3 encodes a PLATZ protein required for tRNA and 5S rRNA transcription through interaction with RNA polymerase III. Plant Cell 2017, 29, 2661-2675. [CrossRef] [PubMed]

75. She, K.C.; Kusano, H.; Koizumi, K.; Yamakawa, H.; Hakata, M.; Imamura, T.; Fukuda, M.; Naito, N.; Tsurumaki, Y.; Yaeshima, M.; et al. A novel factor FLOURY ENDOSPERM2 is involved in regulation of rice grain size and starch quality. Plant Cell 2010, 22, 3280-3294. [CrossRef] [PubMed]

76. Zhang, L.; Ren, Y.; Lu, B.; Yang, C.; Feng, Z.; Liu, Z.; Chen, J.; Ma, W.; Wang, Y.; Yu, X.; et al. FLOURY ENDOSPERM7 encodes a regulator of starch synthesis and amyloplast development essential for peripheral endosperm development in rice. J. Exp. Bot. 2016, 67, 633-647. [CrossRef] [PubMed] 
77. Suzuki, R.; Imamura, T.; Nonaga, Y.; Kusano, H.; Teramura, H.; Sekine, K.T.; Yamashita, T.; Shimada, H. A novel FLOURY ENDOSPERM2 (FLO2)-interacting protein, is involved in maintaining fertility and seed quality in rice. Plant Biotechnol. J. 2020, 37, 47-55. [CrossRef] [PubMed]

78. Morita, R.; Sugino, M.; Hatanaka, T.; Misoo, S.; Fukayama, H. $\mathrm{CO}_{2}$-responsive CONSTANS, CONSTANS-like, and time of chlorophyll a/b binding protein Expression1 protein is a positive regulator of starch synthesis in vegetative organs of rice. Plant Physiol. 2015, 167, 1321-1331. [CrossRef]

79. Jones-Rhoades, M.W.; Bartel, D.P.; Bartel, B. MicroRNAS and their regulatory roles in plants. Annu. Rev. Plant Biol. 2006, 57, 19-53. [CrossRef]

80. Barciszewska-Pacak, M.; Milanowska, K.; Knop, K.; Bielewicz, D.; Nuc, P.; Plewka, P.; Pacak, A.; Vazquez, F.; Karlowski, W.; Jarmolowski, A.; et al. Arabidopsis microRNA expression regulation in a wide range of abiotic stress responses. Front. Plant Sci. 2015, 6, 410. [CrossRef]

81. Qu, D.; Yan, F.; Meng, R.; Jiang, X.; Yang, H.; Gao, Z.; Dong, Y.; Yang, Y.; Zhao, Z. Identification of MicroRNAs and their targets associated with fruit-bagging and subsequent sunlight re-exposure in the "granny smith" apple exocarp using high-throughput sequencing. Front. Plant Sci. 2016, 7, 2. [CrossRef]

82. Peng, T.; Sun, H.; Du, Y.; Zhang, J.; Li, J.; Liu, Y.; Zhao, Y.; Zhao, Q. Characterization and expression patterns of microRNAs involved in rice grain filling. PLoS ONE 2013, 8, e54148. [CrossRef] [PubMed]

83. Meng, F.; Liu, H.; Wang, K.; Liu, L.; Wang, S.; Zhao, Y.; Yin, L.; Li, Y. Development-associated microRNAs in grains of wheat (Triticum aestivum L.). BMC Plant Biol. 2013, 13, 140. [CrossRef] [PubMed]

84. Huang, H.; Long, J.; Zheng, L.; Li, Y.; Hu, Y.; Yu, G.; Liu, H.; Liu, Y.; Huang, Z.; Zhang, J.; et al. Identification and characterization of microRNAs in maize endosperm response to exogenous sucrose using small RNA sequencing. Genomics 2016, 108, 216-223. [CrossRef]

85. Li, D.; Liu, Z.; Gao, L.; Wang, L.; Gao, M.; Jiao, Z.; Qiao, H.; Yang, J.; Chen, M.; Yao, L.; et al. Genome-wide identification and characterization of microRNAs in developing grains of Zea mays L. PLoS ONE 2016, 11, e0153168. [CrossRef] [PubMed]

86. Li, C.; Yue, Y.; Chen, H.; Qi, W.; Song, R. The ZmbZIP22 transcription factor regulates 27-kD $\gamma$-zein gene transcription during maize endosperm development. Plant Cell 2018, 30, 2402-2424. [CrossRef]

87. Yang, J.; Ji, C.; Wu, Y. Divergent Transactivation of Maize Storage Protein Zein Genes by the Transcription Factors Opaque2 and OHPs. Genetics 2016, 204, 581-591. [CrossRef] [PubMed]

88. Yang, T.; Guo, L.; Ji, C.; Wang, H.; Wang, J.; Zheng, X.; Xiao, Q.; Wu, Y. The B3 domain-containing transcription factor ZmABI19 coordinates expression of key factors required for maize seed development and grain filling. Plant Cell 2020, koaa008. [CrossRef]

89. Qiao, Z.; Qi, W.; Wang, Q.; Feng, Y.; Yang, Q.; Zhang, N.; Wang, S.; Tang, Y.; Song, R. ZmMADS47 regulates zein gene transcription through interaction with Opaque2. PLoS Genet. 2016, 12, e1005991. [CrossRef]

90. Dreni, L.; Jacchia, S.; Fornara, F.; Fornari, M.; Ouwerkerk, P.B.; An, G.; Colombo, L.; Kater, M.M. The D-lineage MADS-box gene OsMADS13 controls ovule identity in rice. Plant J. 2007, 52, 690-699. [CrossRef]

91. Yin, L.L.; Xue, H.W. The MADS29 transcription factor regulates the degradation of the nucellus and the nucellar projection during rice seed development. Plant Cell 2012, 24, 1049-1065. [CrossRef] [PubMed]

92. Zha, K.; Xie, H.; Ge, M.; Wang, Z.; Wang, Y.; Si, W.; Gu, L. Expression of maize MADS transcription factor ZmES22 negatively modulates starch accumulation in rice endosperm. Int. J. Mol. Sci. 2019, 20, 483. [CrossRef] [PubMed]

93. Grimault, A.; Gendrot, G.; Chamot, S.; Widiez, T.; Rabillé, H.; Gérentes, M.F.; Creff, A.; Thévenin, J.; Dubreucq, B.; Ingram, G.C.; et al. ZmZHOUPI, an endosperm-specific basic helix-loop-helix transcription factor involved in maize seed development. Plant $\mathrm{J}$. 2015, 84, 574-586. [CrossRef] [PubMed]

94. Feng, F.; Qi, W.; Lv, Y.; Yan, S.; Xu, L.; Yang, W.; Yuan, Y.; Chen, Y.; Zhao, H.; Song, R. OPAQUE11 is a central Hub of the regulatory network for maize endosperm development and nutrient metabolism. Plant Cell 2018, 30, 375-396. [CrossRef]

95. Xing, Q.; Creff, A.; Waters, A.; Tanaka, H.; Goodrich, J.; Ingram, G.C. ZHOUPI controls embryonic cuticle formation via a signalling pathway involving the subtilisin protease ABNORMAL LEAF-SHAPE1 and the receptor kinases GASSHO1 and GASSHO2. Development 2013, 140, 770-779. [CrossRef]

96. Yang, S.; Johnston, N.; Talideh, E.; Mitchell, S.; Jeffree, C.; Goodrich, J.; Ingram, G. The endosperm-specific ZHOUPI gene of Arabidopsis thaliana regulates endosperm breakdown and embryonic epidermal development. Development 2008, 135, 3501-3509. [CrossRef]

97. Kondou, Y.; Nakazawa, M.; Kawashima, M.; Ichikawa, T.; Yoshizumi, T.; Suzuki, K.; Ishikawa, A.; Koshi, T.; Matsui, R.; Muto, S.; et al. RETARDED GROWTH OF EMBRYO1, a new basic helix-loop-helix protein, expresses in endosperm to control embryo growth. Plant Physiol. 2008, 147, 1924-1935. [CrossRef]

98. López-González, C.; Juárez-Colunga, S.; Morales-Elías, N.C.; Tiessen, A. Exploring regulatory networks in plants: Transcription factors of starch metabolism. PeerJ 2019, 7, e6841. [CrossRef]

99. Tsai, H.L.; Lue, W.L.; Lu, K.J.; Hsieh, M.H.; Wang, S.M.; Chen, J. Starch synthesis in Arabidopsis is achieved by spatial cotranscription of core starch metabolism genes. Plant Physiol. 2009, 151, 1582-1595. [CrossRef]

100. Bartlett, A.; O’Malley, R.C.; Huang, S.C.; Galli, M.; Nery, J.R.; Gallavotti, A.; Ecker, J.R. Mapping genome-wide transcription-factor binding sites using DAP-seq. Nat. Protoc. 2017, 12, 1659-1672. [CrossRef] 
101. Landt, S.G.; Marinov, G.K.; Kundaje, A.; Kheradpour, P.; Pauli, F.; Batzoglou, S.; Bernstein, B.E.; Bickel, P.; Brown, J.B.; Cayting, P.; et al. ChIP-seq guidelines and practices of the ENCODE and modENCODE consortia. Genome Res. 2012, 22, 1813-1831. [CrossRef]

102. Tiessen, A. The fluorescent blue glow of banana fruits is not due to symplasmic plastidial catabolism but arises from insoluble phenols estherified to the cell wall. Plant Sci. 2018, 275, 75-83. [CrossRef] [PubMed]

103. Shaw, R.; Tian, X.; Xu, J. Single-cell transcriptome analysis in plants: Advances and challenges. Mol. Plant. 2021, 14, 115-126. [CrossRef] [PubMed]

104. Yu, Q.; Liu, S.; Yu, L.; Xiao, Y.; Zhang, S.; Wang, X.; Xu, Y.; Yu, H.; Li, Y.; Yang, J.; et al. RNA demethylation increases the yield and biomass of rice and potato plants in field trials. Nat. Biotech. 2021. [CrossRef] [PubMed] 